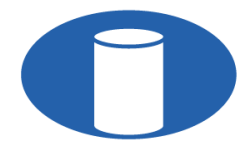

IBRACON Structures and Materials Journal

Revista IBRACON de Estruturas e Materiais

IBRACON

ISSN 1983-4195

ismj.org

ORIGINAL ARTICLE

\title{
A method for considering the influence of distinct casting stages in the flexural design of prestressed concrete cross sections
}

\section{Um método para consideração da influência de moldagens distintas no dimensionamento à flexão de seções transversais de concreto protendido}

\author{
Eduardo Vicente Wolf Trentini ${ }^{\mathrm{a}}$ \\ Guilherme Aris Parsekian ${ }^{\mathrm{a}}$ \\ Túlio Nogueira Bittencourt ${ }^{\mathrm{b}}$ (D)
}

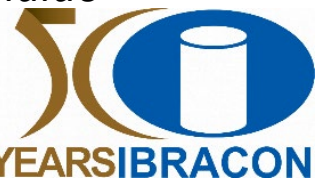

${ }^{a}$ Universidade Federal de São Carlos - UFSCar, Programa de Pós-graduação em Engenharia Civil, São Carlos, SP, Brasil

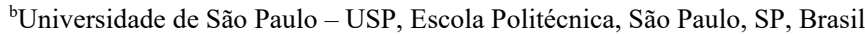

Received 09 September 2021

Accepted 24 January 2022

\begin{abstract}
Composite elements are structures of concrete, or other materials, constructed in different casting stages that act jointly under external loads. These elements are used when it is intended to combine the constructive advantages of precast structures with the monolithic behavior of cast-in-place structures. In regular civil engineering applications, such as the construction of a bridge or viaduct, the precast section is used as shoring before casting the slab in place. This process leads to imposed deformations prior to the ultimate limit state and a discontinuity in the specific strain of the composite cross section. This work proposes a methodology to design composite cross sections, built in two casting stages, evaluating the specific strain provided the construction process that can be easily implemented in precise computational routines. From applying the methodology on study-case numerical example, it is observed that the beam casted in two stages presents a factored moment resistance smaller than an identical beam casted in a single stage. However, further investigations should be conducted to assess the extent of this difference.
\end{abstract}

Keywords: composite sections, construction process, precast, bending, structural design.

Resumo: Elementos compostos são estruturas de concreto, ou outros materiais, executados em moldagens distintas que atuam de maneira conjunta sob ações externas. Esses elementos são utilizados quando se pretende aliar as vantagens construtivas de estruturas pré-moldadas ao comportamento monolítico de estruturas moldadas no local. Em situações comuns na engenharia civil, como a construção de uma ponte ou viaduto, a seção pré-moldada é utilizada como cimbramento para a moldagem no local da laje. Esse processo proporciona deformações prévias ao estado-limite último e descontínuas na seção transversal composta. Este trabalho propõem uma metodologia para dimensionamento de seções compostas, em duas etapas de concretagem, avaliando as deformações proporcionadas pelo processo construtivo que pode ser facilmente implementada em rotinas computacionais precisas. Aplicando a metodologia em um exemplo numérico, é observado que a seção concretada em duas etapas apresenta um momento resistente menor que uma seção idêntica concretada em etapa única. Porém são necessárias mais investigações para avaliar a amplitude desta divergência em outros elementos.

Palavras-chave: seções compostas, processo construtivo, pré-moldado, flexão, dimensionamento.

How to cite: E. V. W. Trentini, G. A. Parsekian, and T. N. Bittencourt, "A method for considering the influence of distinct casting stages in the flexural design of prestressed concrete cross sections," Rev. IBRACON Estrut. Mater., vol. 15, no. 4, e15410, 2022, https://doi.org/10.1590/S198341952022000400010 


\section{INTRODUCTION}

The demand for quality, speed of execution and rationalization of building materials has increased the choice for precast concrete structures. The use of precast elements introduces a repetitive character into the construction process reducing waste and directly reflecting a better productivity of the workforce [1].

To connect the precast elements to the rest of the structure, it is common to cast in place part of the element, creating a monolithic connection. In civil construction these elements are known as pre-beams and pre-slabs and NBR 9062 [2] defines them as composite elements, being: "structures of concrete, or other materials, constructed in different casting stages that act jointly under external loads".

The use of concrete composite elements combines the advantages of precast concrete structures, such as the use of more complex cross sections, reuse of formwork, possible prestress on plant, excellent quality control, reduction of shoring, the monolithic behavior induced by cast in place concrete [3], [4].

The use of composite sections in concrete introduces peculiar situations the structural analysis process. Each influence of the factors below must be checked:

deformations in the precast concrete section prior to the curing of the second stage cast;

different strain resulting from concrete shrinkage and creep, on each stage, due to the difference between materials and casting age, and;

the existence of slip between the interface of the two concrete casts [2].

Regarding occurrence of slip verification between the contact surfaces, many experimental studies were carried out and proposed equations to evaluate the load capacity of the interface to the horizontal shear are available in [5]-[12]. Design codes, such as ACI [13], AASHTO [14] and NBR 9062 [2], include equations to evaluate this capacity. The NBR 9062 [2] prescribes that if the horizontal shear strength is greater than the shear stress load, it can be considered that the composite element presents monolithic behavior, as also observed by [15]-[17].

Different age, rheology, and stress level in each casting stage, causes different volume changes due to shrinkage and creep of the concrete. Since there is a relative strain restriction between the two casting stages, the differential volume variation results in the development of stresses in the section [18]. Models for evaluating the resulting stresses due to differential volume variation are extensively addressed in the literature [19]-[24]. As shown by [25], the creep effect ends up decreasing the tension difference between the precast section and the cast in place section, thus making the stress distribution in the composite cross section more similar to that developed in a single-step casted section. The shrinkage effect is more intense in the first days. Therefore, after the in place casting, the concrete of the second cast shrinks more than the first cast, developing tensile stresses and even cracks that may reduce durability [26]. In bridge construction, the girders usually are joined to the slab in a later cast in place step. This connection occurs in the upper region of the cross section subject to compression in the case of beams demanded by positive bending moment. In this case, the tensile stress mentioned above is beneficial for the analysis of the section in Ultimate Limit State (ULS), therefore, the evaluation of these both effects are not included in the scope of this article assuming that the ULS occurs when the effects of shrinkage and creep have not yet fully developed.

During the construction process, the precast girder is lifted and placed on the supports, and then used as shoring for the cast in place slab. The self-weight load deforms only the girders, once only after the curing of the second casting stage can the additional loads be considered acting on the monolithic composite section. This constructive process results in a cross section that presents a strain, $\varepsilon$, discontinuity along of its z-height due to previous strain imposed to the precast member prior to the slab curing. Figure 1 illustrates the strain and normal stresses of part of a beam, resulting from this construction process. To show the contrast between the developed stresses and strains, in Figure 1 the behavior of beam built within this construction process is compared to that of a beam built in a single casting. 


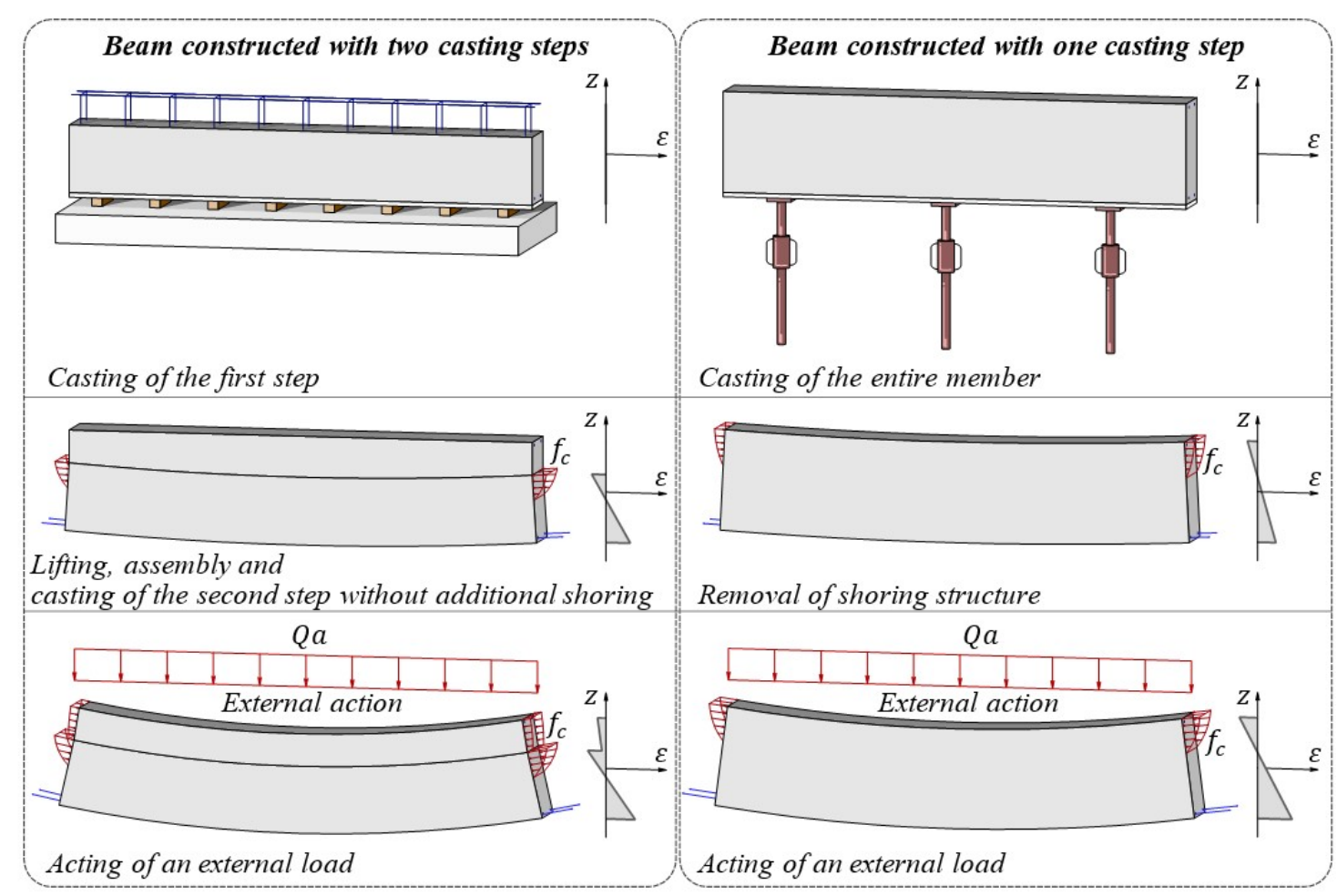

Figure 1. Comparison between construction processes.

The strain discontinuity along the cross section makes the use of conventional design methods unfeasible, since usually continuous strain distribution along the height is assumed. Few works have been developed considering the influence of strain in the precast section when used as shoring for the second casting stage.

In 1955 [27], experimental studies were carried out in which previous prestressing and self-weight strain in the precast section are considered to estimate the stresses, in elastic regime, of composite cast-in-place slab and precast concrete beams, built in two steps. Authors conclude that if the rough interface provides enough friction, the composite cross section can be monolithic considered.

Taha, in 1978 [28], developed a software for the design of composite sections of steel beams and concrete slabs. The permanent strain in the steel section due to the slab casting load were considered, but still in an elastic regime. The design was carried out using the allowable stress method. Dritsos et al. in 1995 [29] reports the efficiency of reinforcing concrete structures by adding a new casting step. The authors considered the slip at the interface between the two casting steps which, in turn, promotes a similar strain discontinuity situation as the construction of non-shored composite cross sections. The equilibrium was evaluated with non-linear constitutive laws for steel and concrete.

Hwang et al. in 2015 [30] proposed a method to evaluate the factored moment resistance and the deformation of precast post-tensioned beams, composed with cast-in-place slab and shored. The authors proposed a complex analysis where, in addition to the non-linear behavior of the materials, the existence of slippage at the interface is also considered with a non-linear response. As this method is intended for shored while casting structures, the analysis developed only evaluates the strain discontinuity due to the prestressing of the precast beam before the slab curing, and due to the interface slippage of the two concretes.

This work proposes a method for flexural design, of precast post-tensioned composite concrete sections with castin-place slab without additional shoring. This method evaluates the strains in the precast beam, which precede the curing of the concrete of the second casting stage due to prestressing and self-weight, considering the monolithic behavior after curing, neglecting the effects of the differential volume variation between the concrete of the two casting stages.

\section{HYPOTHESES OF THE MODEL}

To simplify and limit the problem, the following hypotheses are adopted: 
1. The beams are long one-dimensional structural elements; thus, the cross sections remain plane after deformation Bernoulli's theorem.

2. The connection between passive and prestressing reinforcement with concrete is assumed to be perfect. There is no slippage between the elements and the strain of the reinforcement is the same as the concrete in its vicinity.

3. The interaction between the precast beam and the cast-in-place slab is full, that is, there is no slippage at the interface, thus assuming a monolithic behavior. Any variation in curvature or axial deformation that occurs after cure of the second step is the same for the entire cross section. This hypothesis is valid, according to NBR 9062 [2], if the horizontal shear load is less than the interface strength.

4. Prestressing is applied before the cast of the second step.

5. The cast of the second step is carried out without additional shoring, that is, all self-weight including the self-weight of the slab deforms only the precast section.

6. Between the concrete of the two castings, the differential effects of temperature, shrinkage and creep are neglected. The constitutive law of the materials involved in this analysis are described in NBR 6118:2014 [31] and presented in Figure 2. The constitutive law for compressed concrete has two parts, the first a polynomial curve and the second linear. The stress of the tensioned concrete is neglected. The steel used for passive reinforcement is CA-50 which has an elastic modulus $E_{s}$ and a factored yield stress $f_{y d}$ defined in [31]. The steel of the prestressing reinforcement is CP$190 \mathrm{RB}$ with modulus of elasticity $E_{p}$, factored conventional yield strength $f_{p y d}$ and factored tensile strength $f_{p t d}$ defined in [32]. Both steels have symmetrical behavior

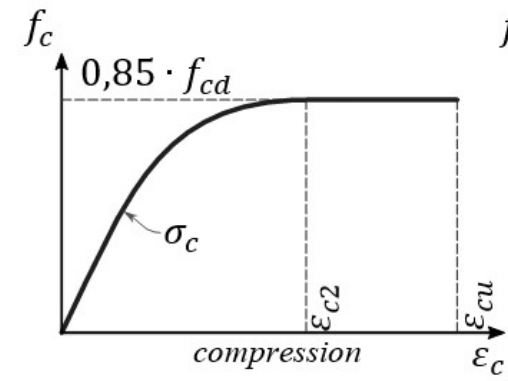

(A) Concrete

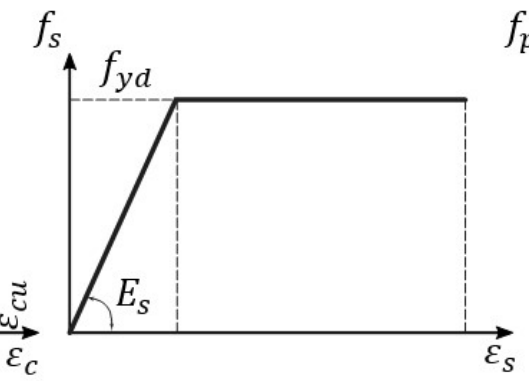

(B) Passive reinforcement steel

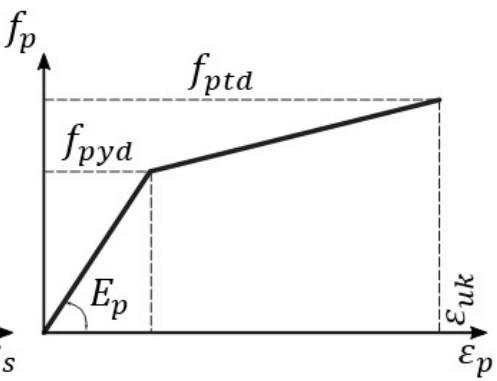

(C) Prestressing reinforcement steel

Figure 2. Stress-strain relationship of the materials.

Where $\sigma_{c}$ is

$\sigma_{c}=0,85 \cdot f_{c d}\left[1-\left(1-\frac{\varepsilon_{c}}{\varepsilon_{c 2}}\right)^{n}\right]$

where $f_{c d}, \varepsilon_{c 2}, \varepsilon_{c u}$ and $n$ are defined in [31] as a function of the characteristic strength of concrete $f_{c k}$.

\section{EQUILIBRIUM AND COMPATIBILITY EQUATIONS}

The internal forces must be in equilibrium with the external forces. In the case of the current structure, the equilibrium must be verified in two situations. The first verification is performed during the casting of the addition on site, which here is called the initial step. Figure 3 illustrates the internal forces and strains of the cross section, when it is submitted to the initial step. This figure also highlights the position of layers A, B, C, and S, which are respectively: surface level between the two castings, finished level of the cast in place addition, level of the beam base and level of the passive reinforcement outermost to the beam.

Checking the equilibrium in the initial step is necessary to evaluate the permanent deformation prior to the slab casting. The strain at layer $\mathrm{A}, \varepsilon_{A, i}$, and the strain in the layer $\mathrm{S}, \varepsilon_{S, i}$, are the variables chosen to define the curvature and the axial deformation of the beam during the initial step. The strain between the layers A and B are null. 

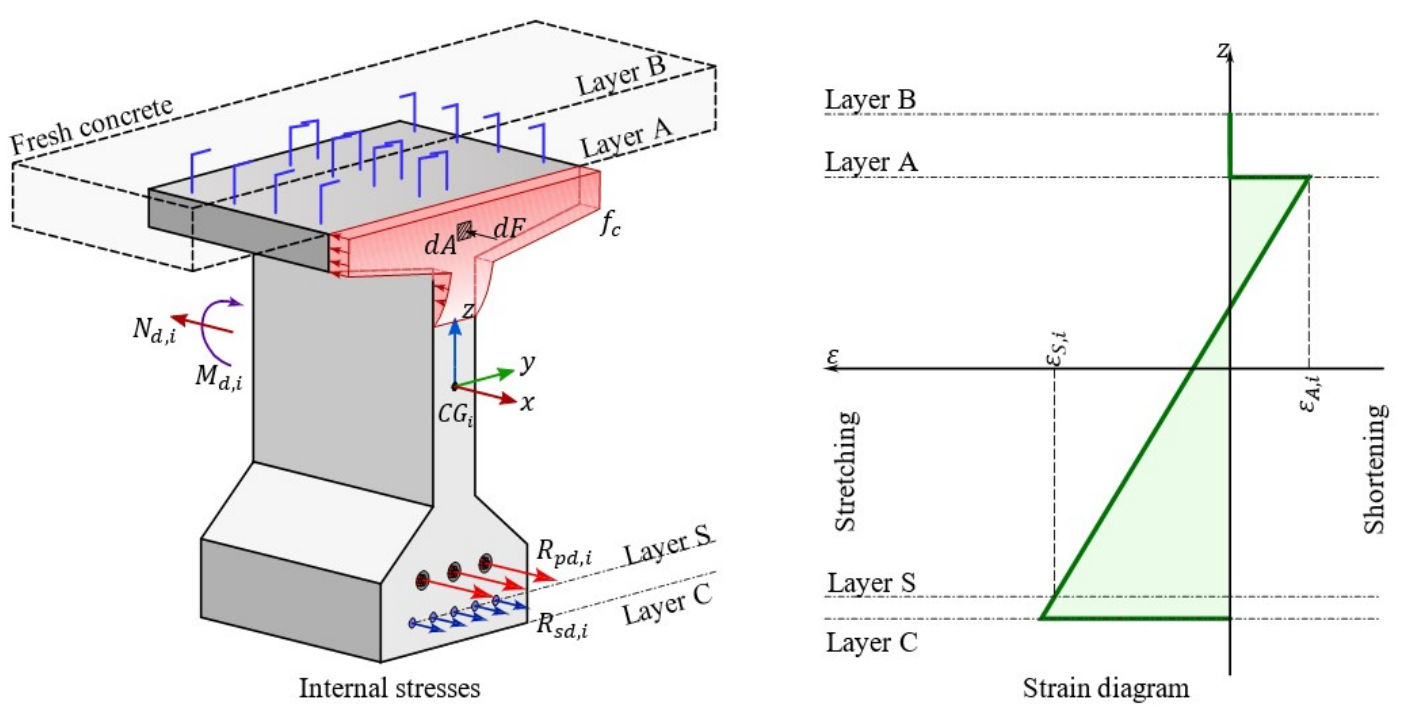

Figure 3. Internal stresses and strain diagram in initial step.

The second equilibrium is developed with the composite section in ULS. This includes the strains on the initial step plus then addition of curvature and axial deformation after the slab casting. This phase is called total step. Figure 4 illustrates internal forces and the strains on the composed cross section, in the total step.
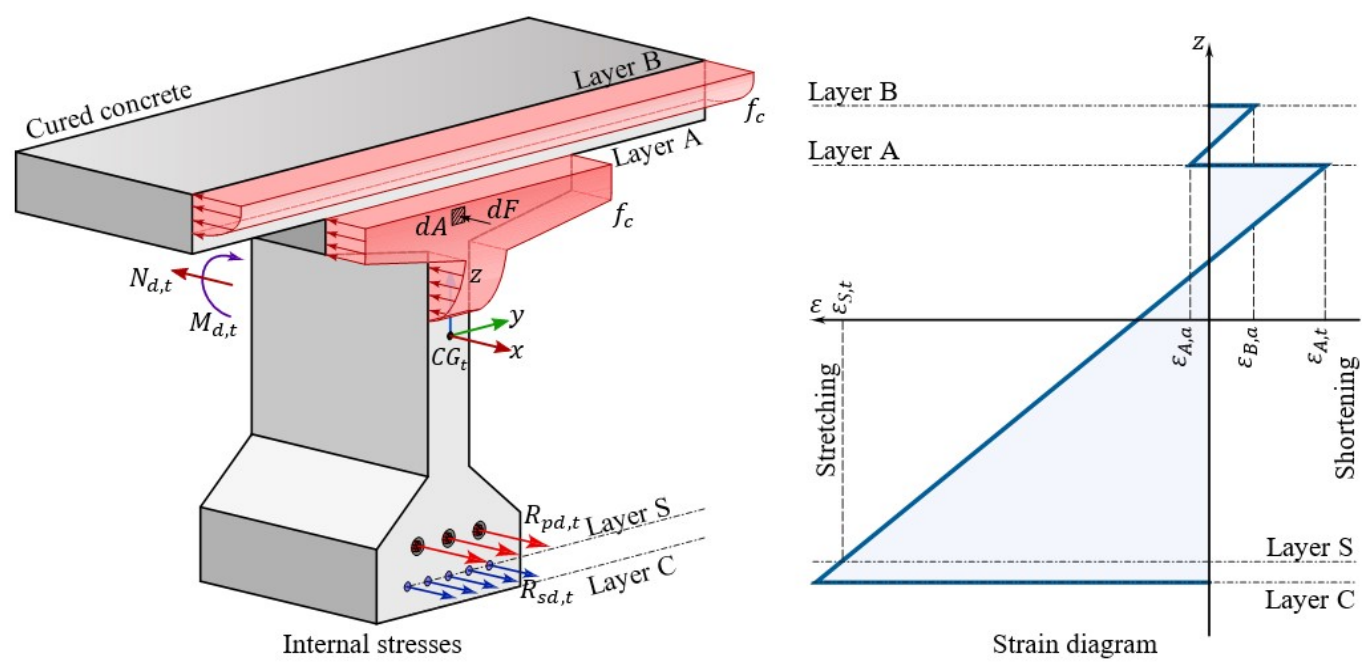

Figure 4. Internal stresses and strain diagram in total step.

The equilibrium equations that apply to the case of symmetrical bending are: (2) Sum of forcer in the $x$ direction, $S N$; (3) Sum of moments in the $y$ direction, $S M$. These equations are defined at the point CG, which represents the centroid of the cross section.

$\sum F_{x}=0 \therefore R_{s d}+R_{p d}+R_{c d}-N_{d}=0 \rightarrow S N=0$ 
$\sum M_{y}=0 \therefore M_{s d}+M_{p d}+M_{c d}+M_{d}=0 \rightarrow S M=0$

Where: $R_{s d}$ normal reaction of the passive reinforcement, $R_{p d}$ normal reaction of the prestressing reinforcement, $R_{c d}$ normal reaction of the concrete, $N_{d}$ factored normal force of the member, $M_{s d}$ moment of the reaction of the passive reinforcement, $M_{p d}$ moment of the reaction of the active reinforcement, $M_{c d}$ moment of the reaction of the concrete, $M_{d}$ factored bending moment of the member. All these moments are defined around the $y$-axis.

The reactions and moments of the reinforcement are obtained by assuming the constitutive law shown in Figure 2 . Assuming perfect bond, the strain of the passive reinforcement is equal to that of the concrete in its vicinity. The strain of the prestressing reinforcement is the sum of the pre-strain of the steel, $\varepsilon_{\text {pre }}$, with the strain of the adjacent concrete.

The contribution of concrete in the internal equilibrium is analyzed by highlighting the infinitesimal element of area $d A$, considering that an infinitesimal force $d F$ is exerted on it. Since $d F$ is function of the concrete stress $f_{c}$, where $d F=f_{c} \cdot d A$, the $R_{c d}$ and $M_{c d}$ are then written as:

$R_{c d}=\int_{A} \mathrm{~d} F \therefore R_{c d}=\int_{A} f_{c} \cdot \mathrm{d} A$,

$M_{c d}=\int_{A} z \cdot \mathrm{d} F \quad \therefore M_{c d}=\int_{A} z \cdot f_{c} \cdot \mathrm{d} A$.

The integrals of the Equations 4 and 5 can be solved by one of two processes: analytical integration or numerical integration by discretizing the area into small elements.

Numerical integration is versatile in terms of allowing to consider different constitutive laws. On the other hand, the quality of the response is related to the number of elements used, and this alternative has a higher computational cost. The computational cost is an inconvenience that can make the use of this alternative unfeasible when incorporated in iterative processes.

Analytical integration presents a negligible computational cost when compared to numerical integration, and its answer is precise within the approximations of the mathematical model. Thus, the integrals of Equations 4 and 5 are here analytically evaluated.

\subsection{Analytical integral of concrete stresses}

The methodology for evaluating the axial reaction $R_{c d}$ and the moment $M_{c d}$ by analytical integration, used here, was developed by Silva and Carvalho in 2019 [33], for the NBR 6118:2014 constitutive law of the concrete.

The method is applied to cross sections described in polygonal form, which have nodes at the vertices and at transition points of the constitutive relation. The transition points of the constitutive relation occur where the section deformation is null, or equal to $\varepsilon_{c 2}$ or equal to $\varepsilon_{c u}$.

With the polygonal defined, the cross section is subdivided into trapezoids, $A_{l}$, contained between the $z$-axis and the lines that define the perimeter of the cross section. Figure 5 illustrates one of these trapezoids contained between the line $l$ and the $z$-axis.

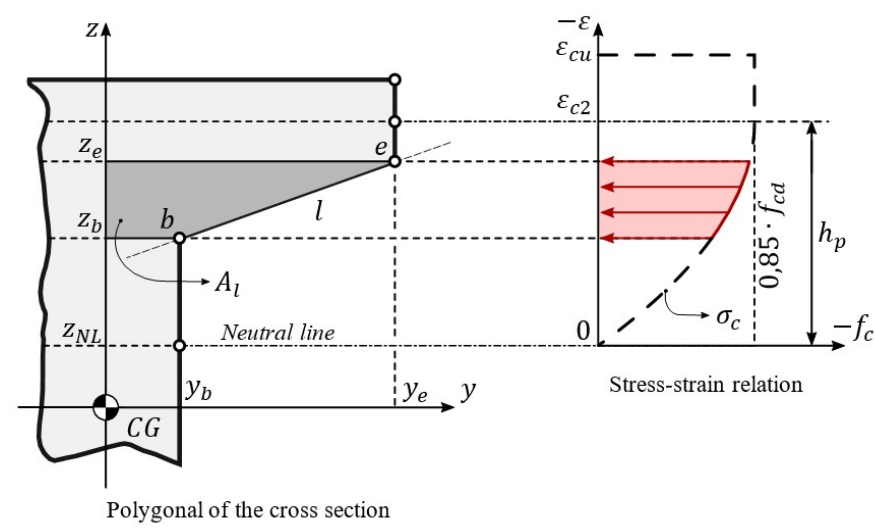

Figure 5. Subdivision of the cross section into trapezoids. 
The contribution of concrete in the equilibrium is evaluated with the Equations 6, 7, 13 and 14 as shown in [33].

For the polynomial part of the constitutive relation, $\sigma_{c}$ of Equation 1, that is, strains smaller than zero and larger than $\varepsilon_{c 2}$.

$R_{c d}=\left.\sum_{P o l}\left(-0,85 \cdot f_{c d} \cdot\left(-\frac{h_{p} \cdot\left(\frac{z_{N L}+h_{p}-z}{h_{p}}\right)^{n_{1}} \cdot\left(c_{1} \cdot n_{2}+c_{2} \cdot\left(h_{p}+z_{N L}+n \cdot z+z\right)\right)}{n_{1} \cdot n_{2}}-c_{1} \cdot z-\frac{c_{2} \cdot z^{2}}{2}\right)\right)\right|_{b} ^{e}$

and

$M_{c d}=\sum_{P o l}\left(\frac{0,85 \cdot f_{c d}}{6 \cdot n_{1} \cdot n_{2} \cdot n_{3}} \cdot\left(3 \cdot c_{1} \cdot\left(n_{1} \cdot n_{2} \cdot n_{3} \cdot z^{2}+2 \cdot h_{p} \cdot\left(\frac{z_{N L}+h_{p}-z}{h_{p}}\right)^{n_{1}} \cdot\left(\left(h_{p}+z_{N L}\right) \cdot n_{3}+n_{1} \cdot n_{3} \cdot z\right)\right)+2 \cdot c_{2} \cdot\right.\right.$

$\left(n_{1} \cdot n_{2} \cdot n_{3} \cdot z^{3}+3 \cdot h_{p} \cdot\left(\frac{z_{N L}+h_{p}-z}{h_{p}}\right)^{n_{1}} \cdot\left(2 \cdot z_{N L}{ }^{2}+2 \cdot h_{p}{ }^{2}+2 \cdot h_{p} \cdot n_{1} \cdot z+n_{1} \cdot n_{2} \cdot z^{2}+2 \cdot z_{N L} \cdot\right.\right.$

$\left.\left.\left.\left.\left(2 \cdot h_{p}+n_{1} \cdot z\right)\right)\right)\right)\right)\left.\right|_{b} ^{e}$

where $z$ is the coordinate of the polygonal node, sometimes of node $b$, sometimes of node $e ; z_{L N}$ the coordinate of the neutral line; $h_{p}$ the height of the polynomial part of the constitutive relationship, highlighted in Figure $5 ; c_{1}$ and $c_{2}$ are the constants of the equation of the line $l$ of $y$ as a function of $z$; and $n_{1}, n_{2}$ e $n_{3}$ are terms depending on the degree of the polynomial of the constitutive relation. The constants of line $l$ and the terms as a function of the exponent of the constitutive relationship are determined with

$c_{1}=\frac{z_{b} \cdot y_{e}-z_{e} \cdot y_{b}}{z_{b}-z_{e}}$ and $c_{2}=\frac{y_{b}-y_{e}}{z_{b}-z_{e}}$

$n_{1}=n+1, n_{2}=n+2$ and $n_{3}=n+3$

where $n$ is defined in [31] as function of $f_{c k}$.

For the part of the constitutive relation where the stress is constant, that is, specific strains smaller than $\varepsilon_{c 2}$ and larger than $\varepsilon_{c u}$.

$R_{c d}=\left.\sum_{\text {Polygonal }}\left(0,85 \cdot f_{c d} \cdot\left(c_{1} \cdot z+\frac{c_{2} \cdot z^{2}}{2}\right)\right)\right|_{b} ^{e}$

and

$M_{c d}=\left.\sum_{\text {Polygonal }}\left(0,85 \cdot f_{c d} \cdot\left(\frac{c_{1} \cdot z^{2}}{2}+\frac{c_{2} \cdot z^{3}}{3}\right)\right)\right|_{b} ^{e}$

In the analyses, the reinforcement area is not subtracted from the concrete cross section area.

\subsection{Strain in the cross section during the construction steps and in ULS}

The equilibrium equations are a function of the cross-sectional strains. As the member is in equilibrium, these equations can be used to determine the deformations in the cross section. 
Assuming that the cross sections remain flat after the loading action, the deformations then vary linearly in relation to height. Thus, in a conventional cross section (consisting of a single casting step), the cross-sectional strains are completely determined by knowing the strain of a pair of points with known height. In the case of a cross section of the type analyzed in this work, the deformation of the initial step is defined by the deformations in the following regions:

- $\varepsilon_{A, i}-$ strain at the layer A, in initial step;

- $\varepsilon_{S, i}$ - strain at the layer $\mathrm{S}$, in initial step;

- with the strains between layers A and B being null.

The strains in the total step are defined by the strain in the following regions:

- $\varepsilon_{A, t}-$ strain at the layer A, in total step;

- $\varepsilon_{S, t}-$ strain at the layer $\mathrm{S}$, in total step;

- $\varepsilon_{B, a}-$ strain at the layer $\mathrm{B}$ in additional and total step;

- $\varepsilon_{A, a}-$ strain at the layer $\mathrm{A}$ in additional and total step.

These strains are illustrated in Figures 3 and 4.

The evolution of strains in the cross section throughout the steps of the construction process is shown in Figure 6. With the composed section, admitting full interaction, the section behaves in a monolithic manner and the strain present in the total step are equal to the strain of the initial step plus strain developed in the additional step.

The additional step is a virtual step that represents the addition of curvature and axial deformation, which occurs in the composed beam, between the initial step and the total step. For the newly formed composite beam, Bernoulli's hypothesis is also true, thus the addition of strain, as a function of height, is linear, and is valid for the entire cross section. Adding the strain of the additional step to the already developed strain in the initial step, the strain of the total step of the cross section is obtained.

The strains in the additional step are defined by the strain in the following regions:

- $\varepsilon_{B, a}-$ strain at the layer $\mathrm{B}$, in additional step;

- $\varepsilon_{S, a}-$ strain at the layer $\mathrm{S}$, in additional step;

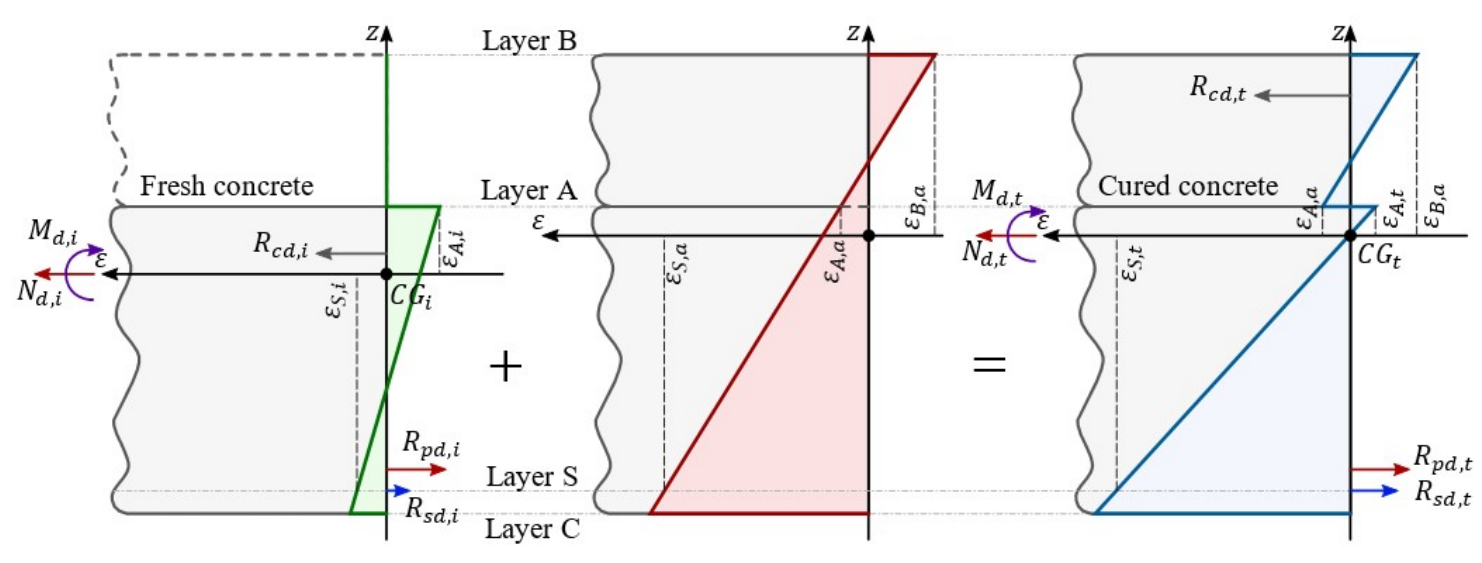
(A) Initial Step
(B) Additional Step
(C) Total Step

Figure 6. Evolution of strain in defined steps.

Having defined the three steps, the following relations between the strains are now written:

$\varepsilon_{A, t}=\varepsilon_{A, i}+\varepsilon_{A, a}$

$\varepsilon_{S, t}=\varepsilon_{S, i}+\varepsilon_{S, a}$ 
where $\varepsilon_{A, a}$ is the strain at the layer $\mathrm{A}$ in additional step given by:

$\varepsilon_{A, a}=\varepsilon_{B, a}+\kappa_{a} \cdot\left(z_{B}-z_{A}\right)$,

where $\kappa_{a}$ is the curvature of the additional step calculated by the equation:

$\kappa_{a}=\frac{\varepsilon_{S, a-\varepsilon_{B, a}}}{z_{B}-z_{S}}$,

where $z_{j}$ is the $z$ coordinate of the layer $j$.

Note that now, using relations (15), (16), (17) and (18), all the strains of the problem are determined if the deformations $\varepsilon_{A, i}, \varepsilon_{S, i}, \varepsilon_{B, a}$ and $\varepsilon_{S, a}$ are known.

Writing a system of equations with (2) and (3), for the initial step, it is possible to determine the strains $\varepsilon_{A, i}$ e $\varepsilon_{S, i}$. This process is called determination of the strains in initial step and is described in item 4 of this work. Once these strains are known, the strains domains of the additional step that promote ULS in the composite section are then defined, a process described in item 5. Once the strains domains are known, the process for evaluate the factored moment resistance for the composite cross section is described in item 6 and the design method is presented in item 7 .

\section{DETERMINATION OF THE STRAINS IN INITIAL STEP}

The initial step is defined as the instant immediately after the cast in place addition. In this situation, the addition concrete is fresh, therefore, it accommodates the strains and does not offer participation in the $R_{c d, i}$ e $M_{c d, i}$. The prestrain, necessary to determine the prestressing force, must be calculated with the prestressing losses of the current instant. Furthermore, the factored internal forces $N_{d, i}$ and $M_{d, i}$, are determined with the loads at this moment: selfweight of the precast section and self-weight of the cast in place addition.

To evaluate the moment resistance of the cross section, it is first necessary to evaluate the strains $\varepsilon_{A, i}$ and $\varepsilon_{S, i}$ that occur in the initial step. The NBR 6118:2014 allows to assume that the stress-strain relationship of concrete is linear if the stress is less than $50 \%$ of the compressive strength of concrete. To overcome this limitation, the non-linear constitutive relationship for the concrete in bending shown in Figure 2 will be assumed [31].

Usually at least the strain at one point in the cross section is known. This does not apply to the current situation since the strains $\varepsilon_{A, i}$ e $\varepsilon_{S, i}$ can assume any values within their limits. The problem requires the evaluation of strains in the initial step for arbitrary bending moment. Thus, the problem consists of the solution of the nonlinear system, written by applying Equations 2 and 3 in the initial step, with two variables to be evaluated, namely $\varepsilon_{A, i}$ e $\varepsilon_{S, i}$. The evaluation of Equations 2 and 3 presupposes a defined problem, that is, the concrete cross section as well as the position, area, and pre-strain, $\varepsilon_{\text {pré, }}$, of the reinforcements must be known.

To solve the system, the use of the damped Newton-Raphson method is proposed. This method consists of an iterative process to search for the root of a function $f\left(x_{n}\right)$, nonlinear, where the tangent $f^{\prime}\left(x_{n}\right)$ of the current iteration $n$ is used to estimate the next candidate solution $x_{n+1}$.

$x_{n+1}=x_{n}-\alpha \cdot \frac{f\left(x_{n}\right)}{f^{\prime}\left(x_{n}\right)}$

Since the function of the problem is a vector function, the damped Newton-Raphson method is written as

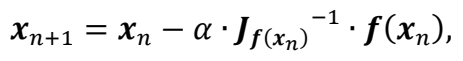

where $\boldsymbol{J}_{\boldsymbol{f}\left(\boldsymbol{x}_{\boldsymbol{n}}\right)}$ is the Jacobian matrix defined on the vector function $\boldsymbol{f}\left(\boldsymbol{x}_{\boldsymbol{n}}\right)$.

For this problem, the Equation 20 is rewritten as: 


$$
\left\{\begin{array}{l}
\varepsilon_{A, i} \\
\varepsilon_{S, i}
\end{array}\right\}_{n+1}=\left\{\begin{array}{l}
\varepsilon_{A, i} \\
\varepsilon_{S, i}
\end{array}\right\}_{n}-\alpha \cdot\left[\begin{array}{ll}
\frac{\partial S N\left(\varepsilon_{A, i}, \varepsilon_{S, i}\right)}{\partial \varepsilon_{A, i}} & \frac{\partial S N\left(\varepsilon_{A, i}, \varepsilon_{S, i}\right)}{\partial \varepsilon_{S, i}} \\
\frac{\partial S M\left(\varepsilon_{A, i}, \varepsilon_{S, i}\right)}{\partial \varepsilon_{A, i}} & \frac{\partial S M\left(\varepsilon_{A, i}, \varepsilon_{S, i}\right)}{\partial \varepsilon_{S, i}}
\end{array}\right]_{n}^{-1} \cdot\left\{\begin{array}{l}
S N\left(\varepsilon_{A, i}, \varepsilon_{S, i}\right) \\
S M\left(\varepsilon_{A, i}, \varepsilon_{S, i}\right)
\end{array}\right\}_{n}
$$

The term $\alpha$ is the damping factor determined as follows:

1. For $\alpha=1$, evaluate $\left\|\left\{\begin{array}{l}S N \\ S M\end{array}\right\}_{n}\right\|_{p}$ and $\left\|\left\{\begin{array}{l}S N \\ S M\end{array}\right\}_{n+1}\right\|_{p}$;

2. Check if $\left\|\left\{\begin{array}{l}S N \\ S M\end{array}\right\}_{n+1}\right\|_{p}<\left\|\left\{\begin{array}{l}S N \\ S M\end{array}\right\}_{n}\right\|_{p}$;

3. if 2 is true, $\left\{\begin{array}{l}\varepsilon_{A, i} \\ \varepsilon_{S, i}\end{array}\right\}_{n+1}$ is accepted as a new iteration;

4. if 2 is false, $\alpha \leftarrow \frac{\alpha}{2}$ and the process is repeated from 2 .

Figure 7 graphically shows the problem-solving strategy, which iteratively, the deformations will be approaching the roots of equations.

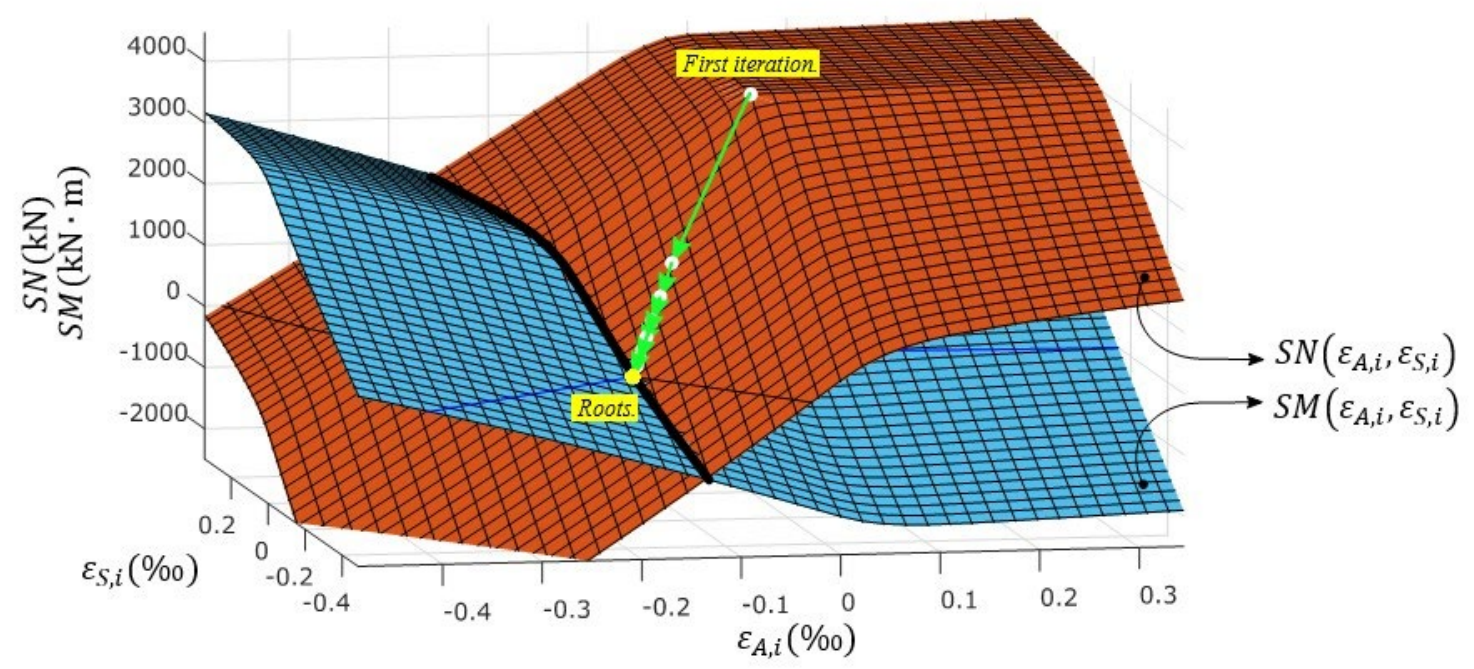

Figure 7. Problem of determination the strains in the initial step.

The Jacobian matrix requires the evaluation of partial derivatives of the $S N$ and $S M$ functions. These derivatives are approximated using central finite differences resulting in Equations 22 to 25 . This technique approximates the tangent slope of the function, at the point of interest, by the slope of a line formed by two points on the function, distant $h$ from each other.

$$
\begin{aligned}
& \frac{\partial S N\left(\varepsilon_{A, i}, \varepsilon_{S, i}\right)}{\partial \varepsilon_{A, i}} \cong \frac{S N\left(\varepsilon_{A, i}+h, \varepsilon_{S, i}\right)-S N\left(\varepsilon_{A, i}-h, \varepsilon_{S, i}\right)}{2 \cdot h} \\
& \frac{\partial S N\left(\varepsilon_{A, i}, \varepsilon_{S, i}\right)}{\partial \varepsilon_{S, i}} \cong \frac{S N\left(\varepsilon_{A, i}, \varepsilon_{S, i}+h\right)-S N\left(\varepsilon_{A, i}, \varepsilon_{S, i}-h\right)}{2 \cdot h} \\
& \frac{\partial S M\left(\varepsilon_{A, i}, \varepsilon_{S, i}\right)}{\partial \varepsilon_{A, i}} \cong \frac{S M\left(\varepsilon_{A, i}+h, \varepsilon_{S, i}\right)-S M\left(\varepsilon_{A, i}-h, \varepsilon_{S, i}\right)}{2 \cdot h}
\end{aligned}
$$


$\frac{\partial S M\left(\varepsilon_{A, i}, \varepsilon_{S, i}\right)}{\partial \varepsilon_{S, i}} \cong \frac{S M\left(\varepsilon_{A, i}, \varepsilon_{S, i}+h\right)-S M\left(\varepsilon_{A, i}, \varepsilon_{S, i}-h\right)}{2 \cdot h}$

The Newton-Raphson method is repeated until the stopping criterion defined in Equation 26 is reached.

$\left\|\left\{\begin{array}{l}S N \\ S M\end{array}\right\}_{n}\right\|_{p}<\xi_{1}$

where $\xi_{1}$ is the error admitted for the vector function.

In the examples in this article, it is admitted $\xi_{1}=10^{-2}$ when evaluating $S N$ and $S M$ in $\mathrm{kN}$ and in $\mathrm{kN} \cdot \mathrm{m}$, respectively. The distance $h$ for evaluating the partial derivatives was adopted equal to $10^{-3}$ for the first iteration and $10^{-9}$ for the other iterations, using double-precision. The first iteration starts from the strains $\varepsilon_{A, i}=0$ and $\varepsilon_{S, i}=0$.

\section{DERMINATION OF THE ULS REGIONS OF COMPOSITE CROSS SECTIONS}

ULS strain domains can be defined. In this work, the concept of domain is replaced by Santos [34] proposal. Santos proposes the grouping of one or more ULS domains in regions that present the same rupture mechanism.

In composite sections, the ULS can be characterized by the individual or combined state of three situations:

- conventional failure due to excessive plastic strain of the passive reinforcement, $\varepsilon_{S, t}=\varepsilon_{s u}$, where $\varepsilon_{s u}=10 \%$ o [31], region 3;

- conventional failure by limit-shortening of concrete in the cast in place addition, $\varepsilon_{B, t}=\varepsilon_{c u}$, region $2 \mathrm{~B}$;

- conventional failure by limit-shortening of concrete of the precast section, $\varepsilon_{A, t}=\varepsilon_{c u}$, region $2 \mathrm{~A}$.

Figure 8 illustrates the deformation of the composite cross section, in ULS, exemplifying the characteristic rupture of each strain region.

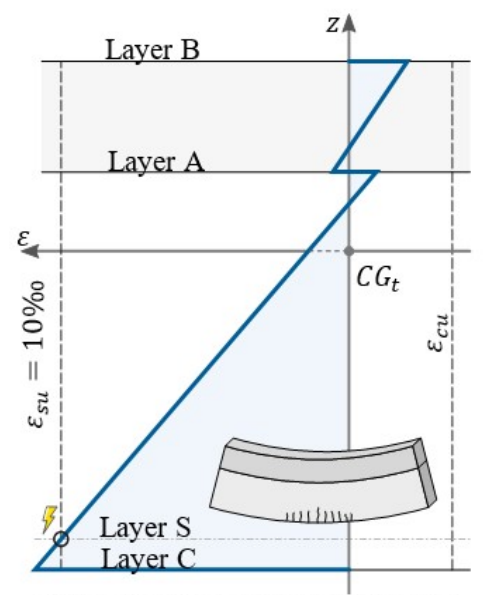

(A) Conventional failure in region 3

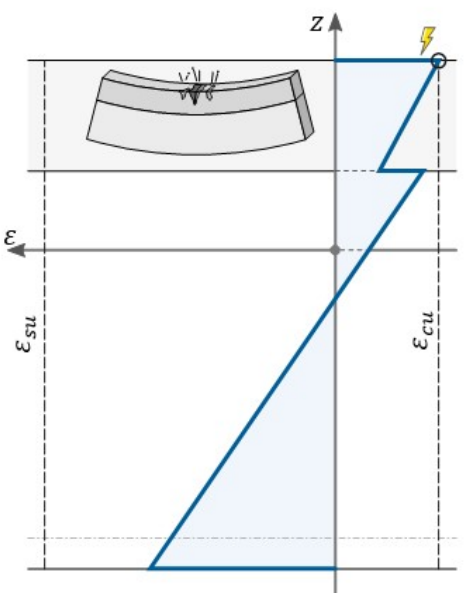

(B) Conventional failure in region $2 \mathrm{~B}$

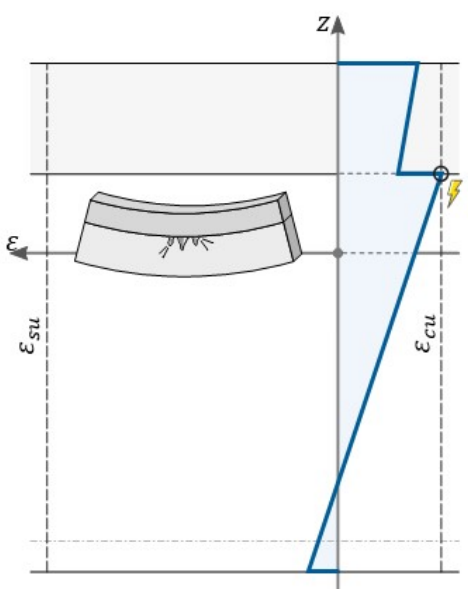

(C) Conventional failure in region $2 \mathrm{~A}$

Figure 8. Deformation of the composite cross section in ULS in the total step.

A cross section, depending on its resulting strains in the initial step, can present three possible trajectories of ULS regions. A trajectory is understood as the sequence in which the regions are presented, analyzing the deformations in ULS, when the normal force $N_{d}$ assumes values in decreasing order from the maximum to the minimum allowed.

Thus, the trajectory of ULS regions is determined by evaluating the level of strain value $\varepsilon_{A, i}$ in relation to the limits $\varepsilon_{A, i, 23 B}$ and $\varepsilon_{A, i, 12 B}$, thus classifying the precast cross section in one of three categories:

- lightly compressed precast section, when $\varepsilon_{A, i}>\varepsilon_{A, i, 12 B}$, with ULS region trajectory from 3 to $2 \mathrm{~B}$; 
- moderately compressed precast section, when $\varepsilon_{A, i, 23 B}<\varepsilon_{A, i} \leq \varepsilon_{A, i, 12 B}$, with ULS region trajectory from 3 to $2 \mathrm{~B}$ to 2A;

- heavily compressed precast section, when $\varepsilon_{A, i} \leq \varepsilon_{A, i, 23 B}$, with ULS region trajectory from 3 to $2 \mathrm{~A}$.

The limits $\varepsilon_{A, i, 23 B}$ and $\varepsilon_{A, i, 12 B}$ are determined by Equations 27 and 28 as a function of the strains obtained in the initial step.

$\varepsilon_{A, i, 12 B}=\left(\varepsilon_{c u}-\varepsilon_{C, t, \min }+\varepsilon_{C, i}\right) \cdot \frac{z_{B}-z_{A}}{z_{B}-z_{C}}$

$\varepsilon_{A, i, 23 B}=\left(\varepsilon_{c u}-\varepsilon_{y u}+\varepsilon_{S, i}\right) \cdot \frac{z_{B}-z_{A}}{z_{B}-z_{S}}$

where $\varepsilon_{s u}$ is the maximum strain allowed in the passive reinforcement, $\varepsilon_{C, t, m i n}$ the strain at layer $\mathrm{C}$ of the boundary between regions 1 and 2 , being $\varepsilon_{C, t, \min }=0$, and $\varepsilon_{C, i}$ the strain at layer $\mathrm{C}$ of the initial step given by:

$\varepsilon_{C, i}=\varepsilon_{A, i}+\kappa_{i} \cdot\left(z_{A}-z_{C}\right)$,

where $\kappa_{i}$ is the curvature of the initial step evaluated by the equation:

$\kappa_{i}=\frac{\varepsilon_{S, i}-\varepsilon_{A, i}}{z_{A}-z_{S}}$.

Region 1 is not of interest to this work as it exceeds the limits of $x / d$ for beams of item 14.6.4.3 of NBR 6118 [31].

The strain regions in ULS for the composite section are defined in relation to the strains of the additional step. Figure 9 represents the strain regions in ULS for composite beams with lightly, moderately and heavily compressed precast section.

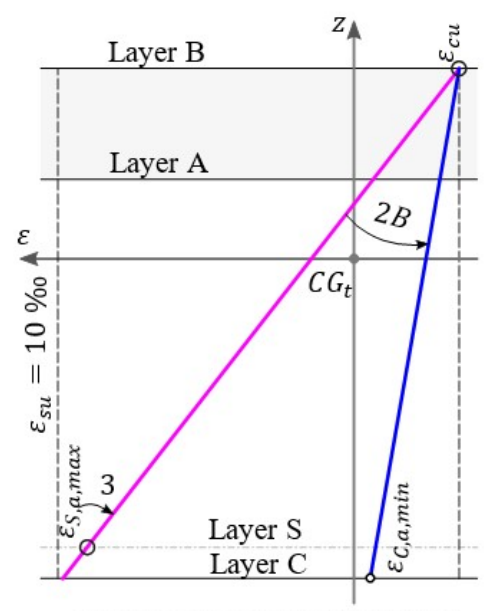

(A) Lightly compressed section

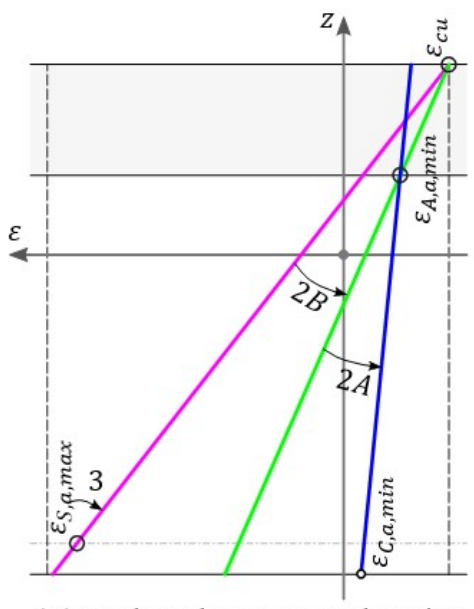

(B) Moderately compressed section

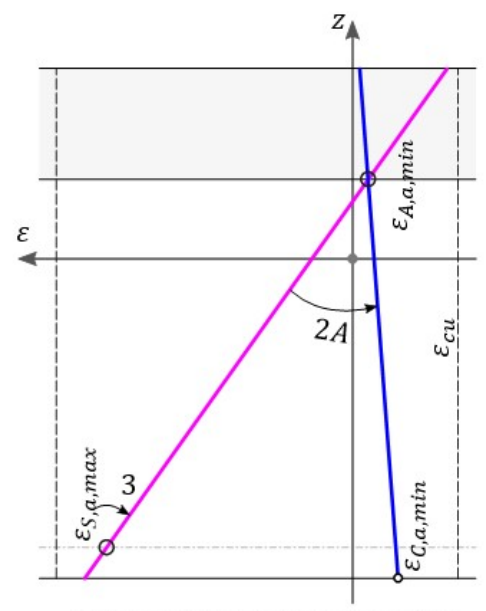

(C) Heavily compressed section

Figure 9. Strain regions in ULS in the additional step.

Each strain region in ULS is defined by a strain group of that have the same value at a certain level of the cross section. Each region has a limited curvature as a function of the compression level of the precast section.

In Figure $9, \varepsilon_{A, a, \min }, \varepsilon_{S, a, \max }$ and $\varepsilon_{C, a, \min }$ are the strains in the additional step, which provides that the strains in the total step are respectively equal $\varepsilon_{c u}, \varepsilon_{s u}$ and $\varepsilon_{C, t, \min }$ at the layers $\mathrm{A}, \mathrm{S}$ and $\mathrm{C}$. These are defined with 
$\varepsilon_{A, a, \min }=\varepsilon_{c u}-\varepsilon_{A, i}$

$\varepsilon_{S, a, \max }=\varepsilon_{s u}-\varepsilon_{S, i}$

$\varepsilon_{C, a, \min }=\varepsilon_{C, t, \min }-\varepsilon_{C, i}$.

Knowing the limits of the strain regions in ULS, it is possible to evaluate in which region the solution of a defined problem is located. This region is obtained by evaluating the sign of the $S N$ function when the strain in the additional step is equal to the limit between adjacent regions. Observing the behavior of the signal of this function, it is then possible to evaluate the region in which Equation 2 is satisfied, which is the region where the curvature and axial deformation solution to the problem is found.

\section{DETERMINATION OF FACTORED MOMENT RESISTANCE FOR THE COMPOSITE CROSS SECTION}

For a defined problem, that is, where the cross section and the characteristics of the reinforcements are known, it is now possible to determine the factored moment resistance $M_{R d}$ of the composite section. Having determined the region in which the ULS deformation is located, the problem boils down to looking, within the solution space contained in the defined region, for the curvature that determines the root of the Equation 2.

The root can be obtained by several iterative numerical methods such as the bisection method, the false position method, the secant method or even the Newton-Raphson method already discussed here. As it is necessary that the solution process does not exceed the limits of the evaluated region and as Equation 2, as it is evaluated here, is not derivable, the false position method becomes the most suitable within the considered methods.

The false position method fetches the root of the function $f(x)$ contained in a known initial range $\left[a_{0}, b_{0}\right]$, where iteratively the search range is reduced so that the root of the function is still contained in the new range $\left[a_{k}, b_{k}\right]$. The new range is defined in iteration $k$ by

$c_{k}=b_{k}-\frac{f\left(b_{k}\right) \cdot\left(b_{k}-a_{k}\right)}{f\left(b_{k}\right)-f\left(a_{k}\right)}$

where $c_{k}$ is the root of the secant that passes through the points $\left[a_{k}, f\left(a_{k}\right)\right]$ and $\left[b_{k}, f\left(b_{k}\right)\right]$. Once $c_{k}$ is determined, the response interval is reduced by making $a_{k+1}=c_{k}$ and $b_{k+1}=b_{k}$, if $f\left(a_{k}\right)$ and $f\left(c_{k}\right)$ have the same sign, otherwise, $a_{k+1}=a_{k}$ and $b_{k+1}=c_{k}$.

Figure 10 illustrates the solution strategy of the false position method, assuming linear behavior for the function in the assigned solution interval, and successively shortens this interval until it reaches a stopping criterion such

$f\left(c_{k}\right)<\xi_{2}$

where $\xi_{2}$ is the error allowed for the function $f(x)$ in this process.

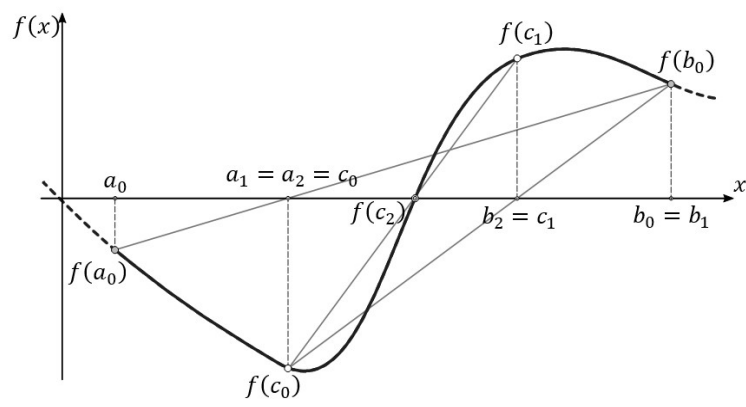

Figure 10. Solution strategy of the false position method. 
To define the deformation in ULS using the false position method, the function $f(x)$ assumes Equation 2 written in the total step, the variable $x$ is the curvature of the additional step $\kappa_{a}$ and the search interval $\left[a_{0}, b_{0}\right]$ is defined as the limiting curvatures of the strain region in ULS for the section in question $\left[\kappa_{a, \min }, \kappa_{a, \max }\right]$.

Once the additional step strains are defined, the moment $M_{d}$ that satisfies Equation 3 written in total step is the factored moment resistance $M_{R d}$ of the composite cross section.

\section{DESIGN METHOD OF COMPOSITE CROSS SECTION}

The factored moment resistance evaluation process, described in item 6 , requires a complete definition of the problem, including the area and position of the reinforcement. For design, it is necessary to organize the problem to determine the amount of passive reinforcement needed so that the composite section can withstand the acting factored moment $M_{S d}$.

Using the processes described in items 4,5 and 6 to determine the $M_{R d}$ it is possible to use the false position method to determine the area of passive reinforcement that satisfies the design equation

$M_{R d}-M_{S d}=0$.

To design the passive reinforcement area, using the false position method, the function $f(x)$ assumes Equation 36 , the independent variable $x$ is the passive reinforcement area $A_{s}$ and the search interval $\left[a_{0}, b_{0}\right]$ is defined as the assumed minimum and maximum reinforcement areas for this cross section $\left[A_{s, \min }, A_{s, \max }\right]$.

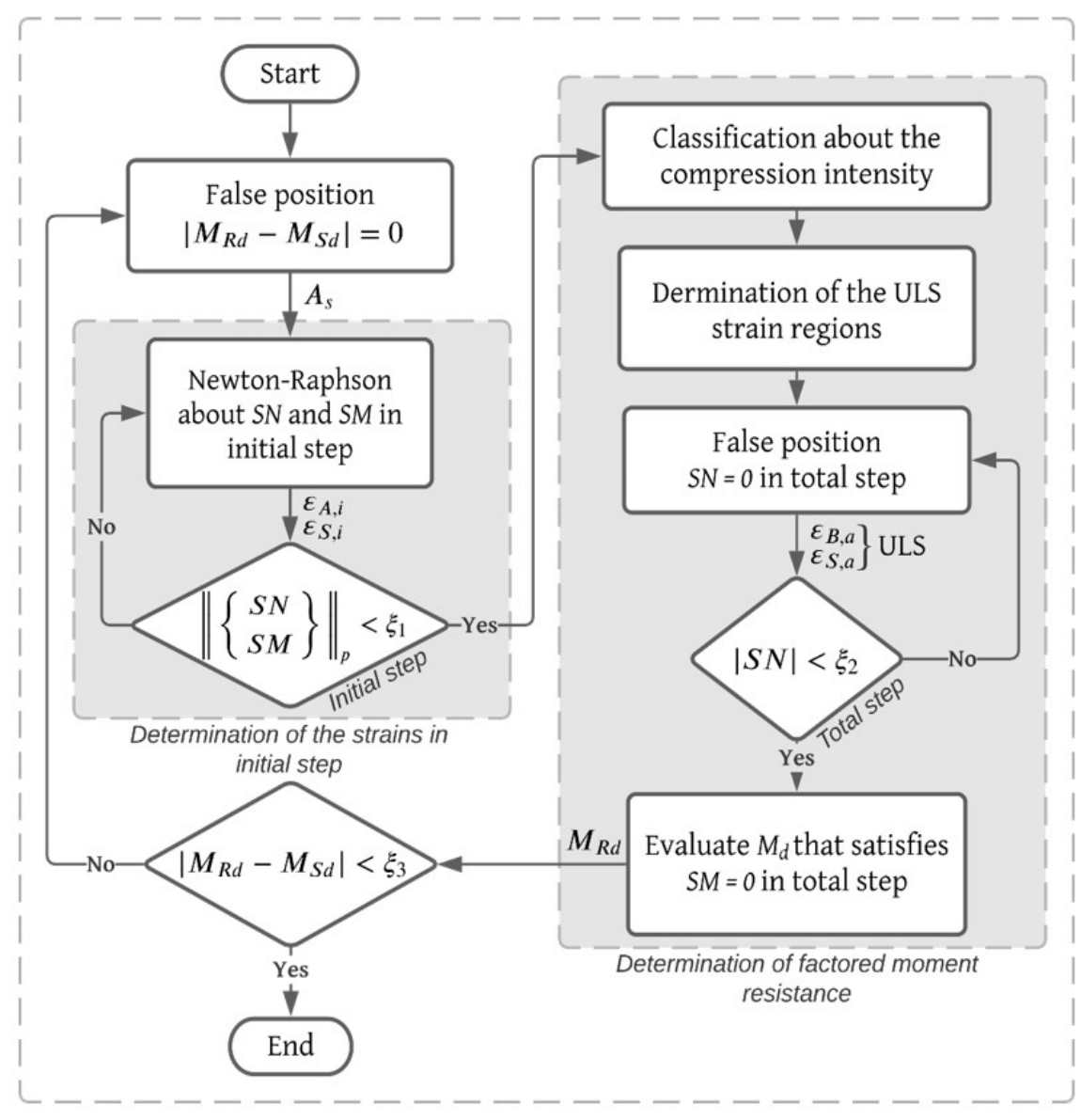

Figure 11. Flowchart of the composite section design process. 
During the design process, summarized in Figure 11, the $S M$ function is evaluated for different areas of passive reinforcement. The discretization procedure of the reinforcement elements in the cross section is presented in the next item, 7.1, since the positioning of these elements is necessary for the evaluation of Equation 3.

\subsection{Discretization model of reinforcement elements with continuous variation}

The reinforcements are positioned in the cross section in layers that must respect the horizontal and vertical spacing of [31]. Furthermore, as this is a real problem, the number of rebars is defined by an integer number. The problem written with an amount of reinforcement defined by an integer, presents a discontinuous relationship between reinforcement area and moment resistance. This discontinuity makes it difficult to use numerical methods to determine the answer to the design problem.

To promote a continuous relationship between $A_{s}$ and $M_{R d}$, the discretization of the individual elements representing the steel rebars is replaced here by $q$ rectangular elements. These elements have the sum of their areas equivalent to $A_{s}$, they are equally spaced and arranged in a reinforced region of the cross section that estimates the real positioning of the discrete rebars

The reinforced region is defined by the dimensions $b$ and $h$, where $b$ is the displacement of the axis of the outermost reinforcement and $h$ the axis of the highest reinforcement layer in the cross section. Dimensions $b$ and $h$ are determined by a linear function in relation to $A_{s}$ obtained from the extreme values $b_{\min }, h_{\min }, b_{\max }$ e $h_{\max }$, established by the actual positioning of the minimum and maximum reinforcement in the cross section, Figure 12.

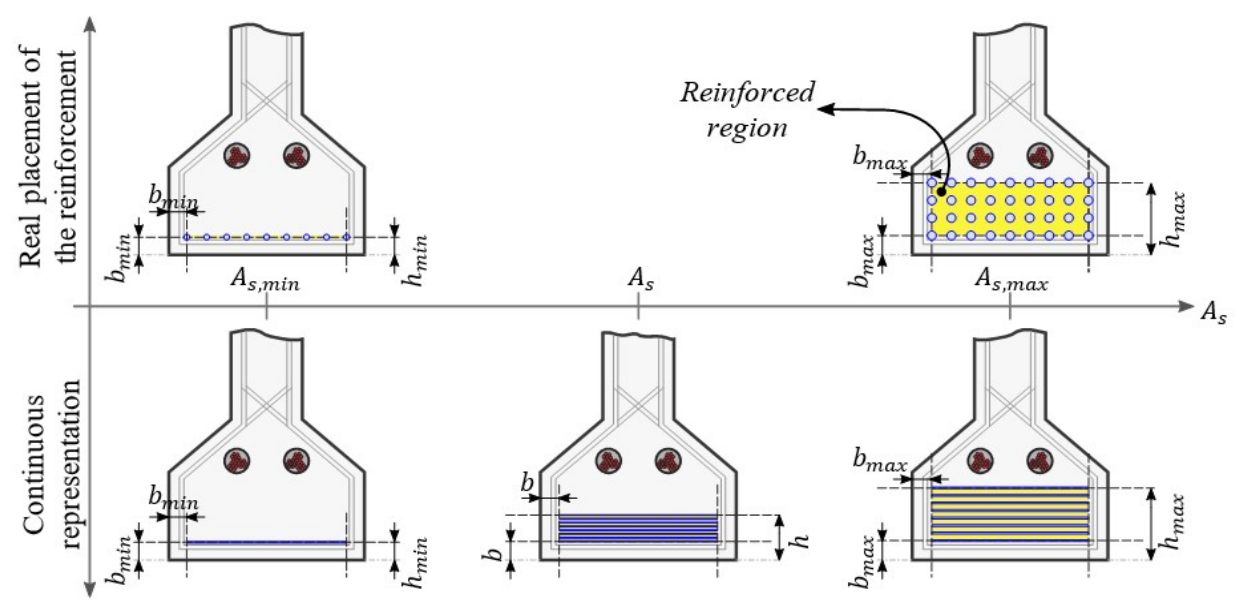

Figure 12. Real positioning and continuous representation of passive reinforcement.

The use of rectangular elements makes the relationship between $A_{s}$ and $M_{R d}$ continuous but introduces a difference in the position of the resulting $R_{s d}$, in relation to the real positioning of the passive reinforcement rebars. Thus, at the end of the process, the factored moment resistance of the beam must be verified with the real positioning of the reinforcement rebars.

\section{EXAMPLES}

The method proposed here to design composite cross sections was implemented in a routine in MATLAB. This routine was then used to develop the following examples.

\subsection{Comparison with the experimental results}

In order to roughly estimate the influence of the simplifying hypothesis of the model, the ultimate moment evaluated by this methodology will be compared with the experimental results obtained by [35] and [36]. In their work, two fullscale reinforced concrete beams were tested to failure in bending. These beams were casted in two steps, with the precast section being loaded prior to the second casting, simulating the effect investigated in this paper. 


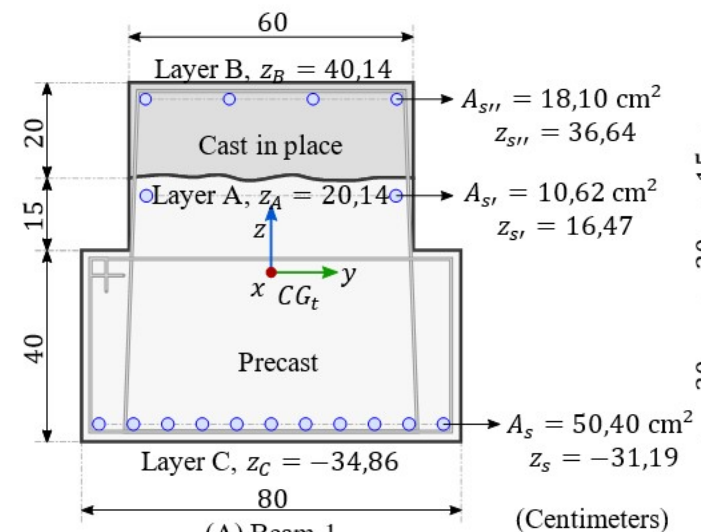

(A) Beam-1

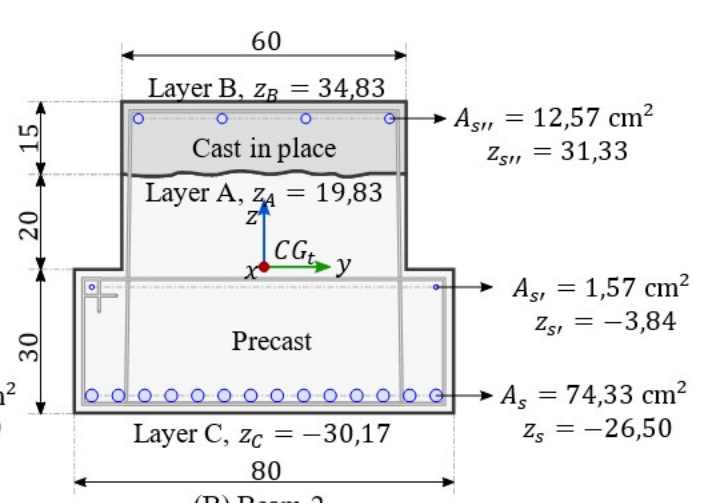

(B) Beam-2

Figure 13. Cross-section of beam-1 and beam-2.

The cross sections of the tested beams are shown in Figure 13. Table 1 shows the estimated strength of the concrete of the beams measured by the strength of the cylindrical specimens at different ages coincident with the test steps. The yielding stress of the steel reinforcement, obtained from tensile tests on samples extracted from the rebars, is $f_{y}=$ $490 \mathrm{MPa}$. The bending moment acting on the precasted beam in the initial step is $M_{i}=531 \mathrm{kN} \cdot \mathrm{m}$ for the beam- 1 and $M_{i}=385 \mathrm{kN} \cdot \mathrm{m}$ for the beam-2, according to [35] and [36].

Table 1. Strength of the cylindrical specimens at different ages.

\begin{tabular}{cccc}
\hline & First cast - initial step & First cast - total step & Second cast - total step \\
\cline { 2 - 4 } & $\boldsymbol{f}_{\boldsymbol{c}, \boldsymbol{i}}(\mathbf{M P a})$ & $\boldsymbol{f}_{\boldsymbol{c}, \boldsymbol{t}}(\mathbf{M P a})$ & $\boldsymbol{f}_{\boldsymbol{c}, \boldsymbol{t}}(\mathbf{M P a})$ \\
\hline Beam-1 & 51 & 59 & 32 \\
\hline Beam-2 & 66 & 68 & 25 \\
\hline
\end{tabular}

Removing the effect of the Rüsch coefficient from the concrete constitutive relationship and using the strength safety factor $\gamma_{c}=\gamma_{s}=1$ the ultimate moment of beam-1 and beam-2 is estimated as shown in Table 2. Figures 14 and 15 show the strains of the cross section, as well as the resulting forces in equilibrium in the initial, additional and total steps evaluation of the ultimate moment of beam-1 and beam-2, respectively.

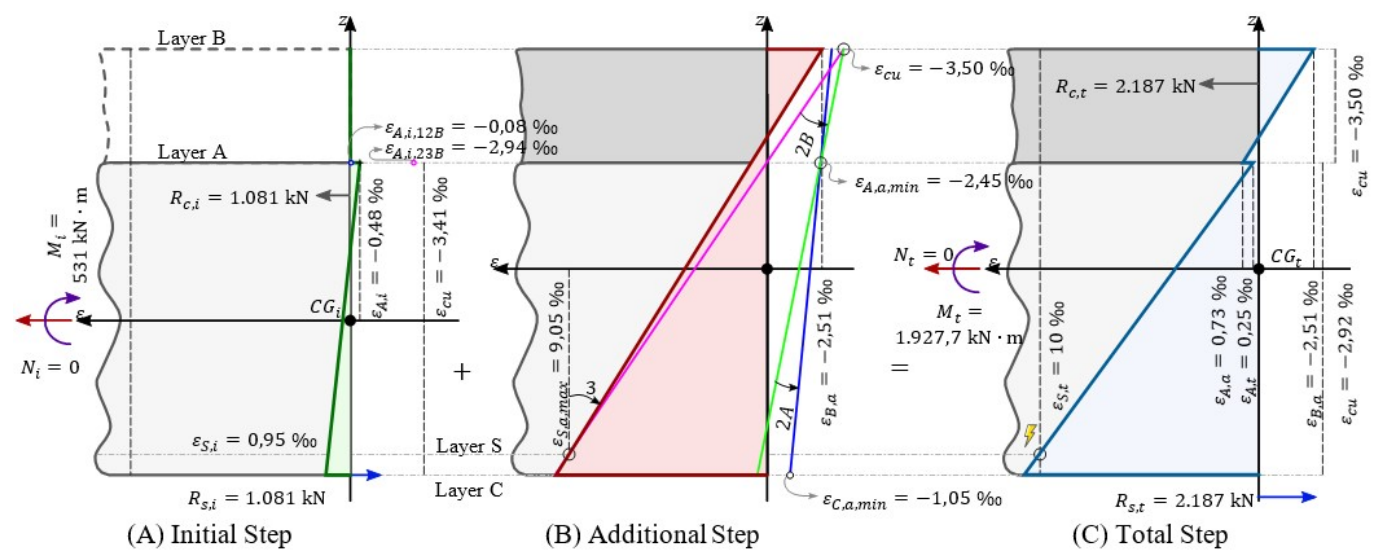

Figure 14. Strain diagram in ULS for the beam-1. 


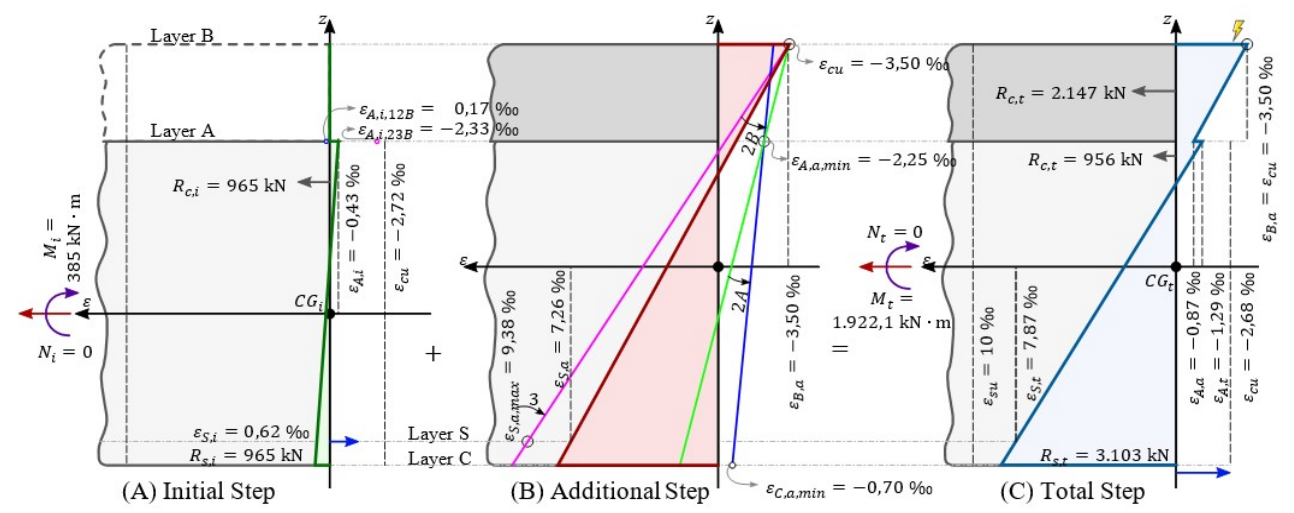

Figure 15. Strain diagram in ULS for the beam-2.

Table 2. Summary of test and estimated ultimate moment.

\section{Ultimate moment in total step $M_{t}(\mathrm{kN} \cdot \mathrm{m})$}

Experimental [35] and [36]

Estimated by this work

Error (\%)

\begin{tabular}{ccccc}
\hline Beam-1 & 1953,5 & 1927,7 (limited by the steel strain equal to $10 \%$ ) & 1,3 \\
\hline Beam-2 & 2346,2 & 1922,1 (limited by the concrete strain equal to $3,5 \%$ ) & 18,1 \\
\hline
\end{tabular}

The differences shown in Table 2 can be explained by the simplifications of the proposed model. The constitutive relationship used for the concrete limits the maximum strain to $\varepsilon_{c u}$, in the experiment, it is likely that the maximum strain of the concrete was higher. This limitation hinders the development of larger reactions of compressed concrete close to layer $\mathrm{A}$ because the curvature is limited by the maximum deformation in layer $\mathrm{B}$. This effect is more pronounced in beam2 because, in this beam, the failure was characterized by the maximum strain of the concrete of the layer B.

\subsection{Numerical Example}

To evaluate the differences introduced in the design when a cross section is casted in a single step and in two steps, it is proposed the design of the cross section in Figure 16. In this example the factored moment in the precast section when the second step is being casted is $15.792 \mathrm{kN} \cdot \mathrm{m}$, and the factored moment resistance in ULS of composite beam need to be $42.658 \mathrm{kN} \cdot \mathrm{m}$.

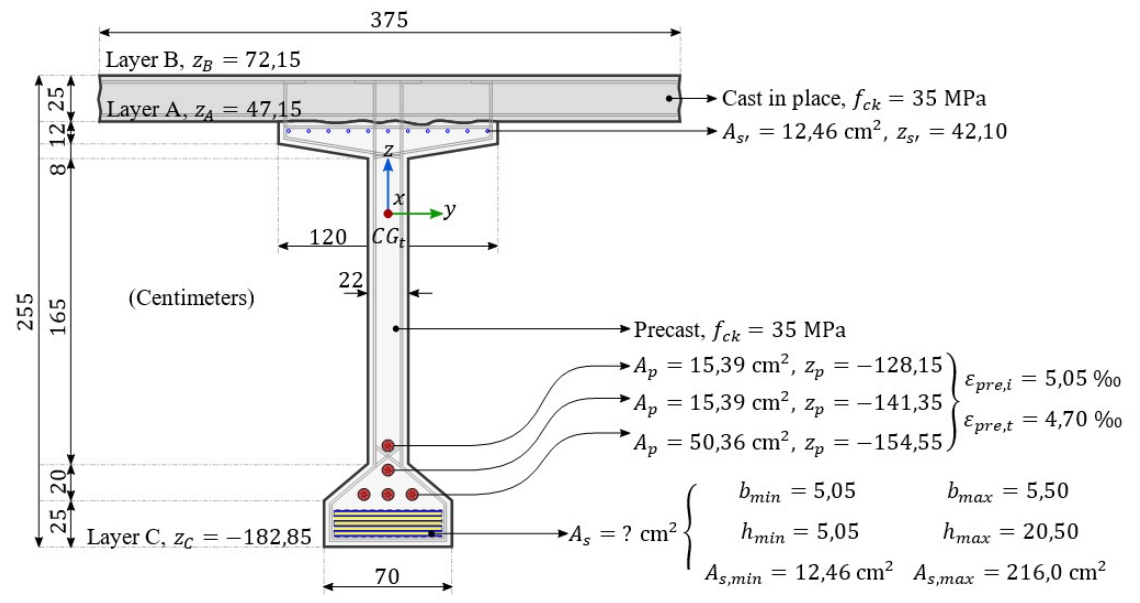

Figure 16. Proposed beam for numerical example. 
Figures 17 and 18 show the strains in the ULS, as well the resulting forces in equilibrium in the cross section when the beam in Figure 16 is design considering single-step and two-step casting, respectively.

Developing the design of the beam assuming that the entire beam is casted in a single step, $177,1 \mathrm{~cm}^{2}$ of passive reinforcement area is needed.

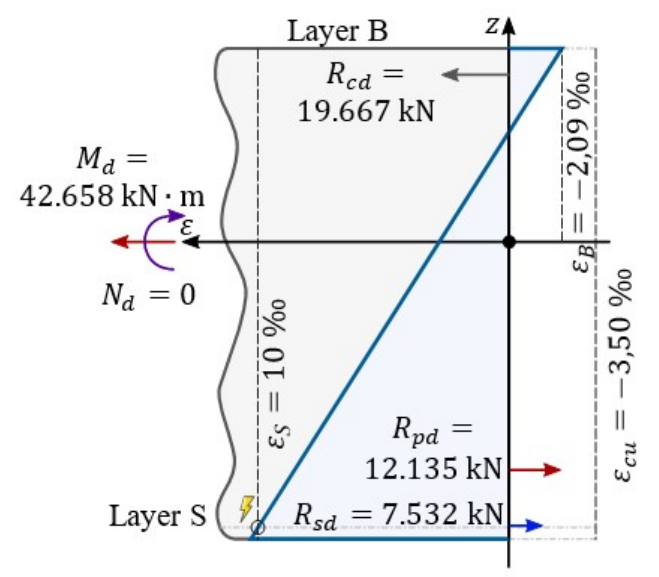

Figure 17. Strain diagram in ULS for the example assuming casting in single step. $A_{s}=177,1 \mathrm{~cm}^{2}$.

In contrast, if the beam in Figure 16 is built by two casting steps, with the precast beam not being shored during the second casting step, the design results in a $189,0 \mathrm{~cm}^{2}$ of passive reinforcement area.

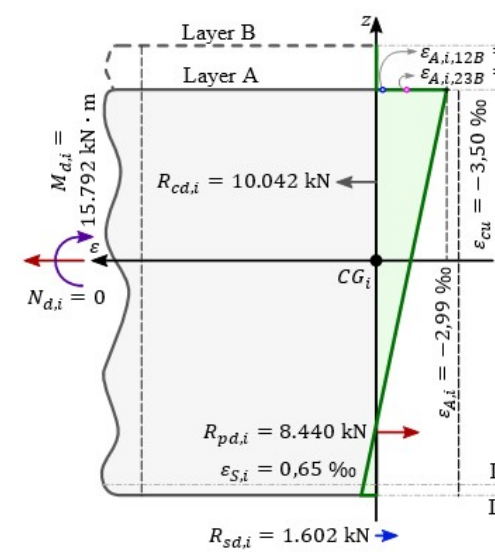

(A) Initial Step

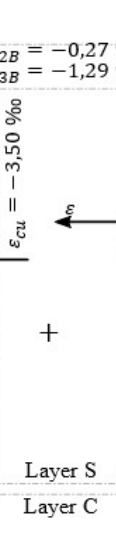

(B) Additional Step

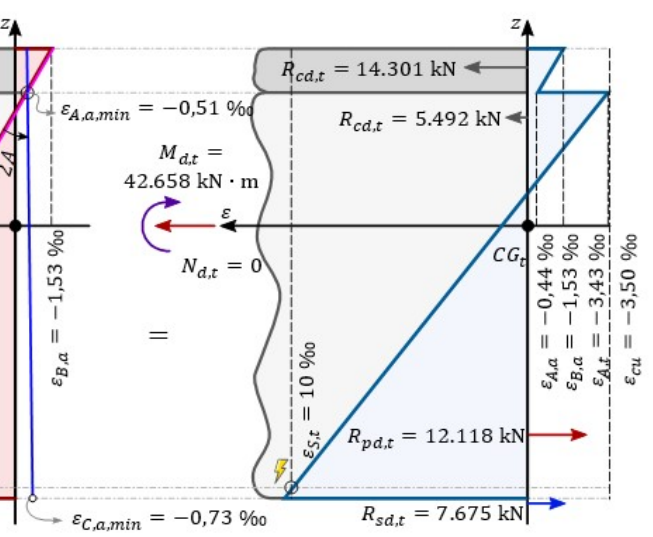

(C) Total Step

Figure 18. Strain diagram in ULS for the example assuming two casting steps. $A_{s}=189,0 \mathrm{~cm}^{2}$.

Analyzing the two designs, it is observed that 6,7\% more passive reinforcement is required, when the beam is built in two casting steps, in relation to de construction in a single cast.

Using the same reinforcement area, $A_{s}=189,0 \mathrm{~cm}^{2}$, it is possible to evaluate and compare the factored moment resistance of the beam in Figure 16, considering the construction in single casting step and in two casting steps. Evaluating the beam constructed in a single step, the factored moment resistance is $43.963 \mathrm{kN} \cdot \mathrm{m}$. When the factored moment resistance is evaluated considering two casting steps, it is equal to $42.658 \mathrm{kN} \cdot \mathrm{m}$. For the example in 
Figure 16, the beam with two casting stages provides a factored resistance moment 3,0\% lower than the beam with a single casting step with the same reinforcement area.

\section{CONCLUSIONS}

Here it is proposed a methodology to design prestressed sections constructed in two casting steps, built without additional shoring, where the strain discontinuity in the cross section, introduced by the construction process, is considered.

The proposed design process consists of iteratively varying the area of passive reinforcement until the factored moment resistance is equal to the requested factored moment. Initially the strains in the precast section are evaluated and, in sequence, the strains in ULS that satisfy the equilibrium and compatibility equations are found.

The damped Newton-Raphson method for evaluating the deformations in the initial step proved to be efficient and numerically stable. The false position method, here used to satisfy the equilibrium and the design equation, is sufficiently efficient and necessary because the search need to be developed within the validity limits of the equations, different from the Newton Raphson method, which does not respect the boundary conditions.

Also, within the solutions adopted to make the method viable, the discretization of the reinforcement elements with continuous variation allowed the solution of the design equation using iterative numerical processes seamlessly.

With all the solutions proposed here, this method can be easily implemented in computational routines for verification and design of composite elements with precision.

Regarding the comparison of the experimental results, the accuracy of the model is high when the failure is characterized by the limit strain of the reinforcement, and lower when the limit strain occurs in concrete. It should be noted that this divergence is due to a simplification of the constitutive relationship of the NBR 6118:2014 and that the estimated resistance is lower than that measured in the test. To obtain an ultimate moment with better experimental and theoretical fitting a more realistic concrete constitutive law is recommended.

The numerical example results show that the section built in two steps, resulted in a moment resistance $3,0 \%$ lower in relation to the verification considering a single casting step. These results may vary when compared to other cross sections, different ratios between the height of each cast stage, different strain in the precast section and different prestressing level. To evaluate the relation between each of these variables in the factored moment resistance further investigation is needed.

For a better understanding of the extent of the effects investigated here, it is very important that more experimental tests of concrete beams casted in two stages with higher loading level in the precast section are carried out due to the lack of tests like this in the literature. It is also proposed that future investigations evaluate experimentally and numerically the effects of time-dependent strain, such as shrinkage and creep, in the moment resistance of concrete composite cross sections.

\section{ACKNOWLEDGEMENTS}

This study was financed in part by the Coordenação de Aperfeiçoamento de Pessoal de Nível Superior - Brasil (CAPES) - Finance Code 001.

\section{REFERENCES}

[1] R. Tomek, "Advantages of precast concrete in highway infrastructure construction," Procedia Eng., vol. 196, pp. 176-180, 2017, http://dx.doi.org/10.1016/j.proeng.2017.07.188.

[2] Associação Brasileira de Normas Técnicas, Projeto e Execução de Estruturas de Concreto Pré-Moldado, ABNT NBR 9062:2017, 2017.

[3] T. I. Campbell, V. K. R. Kodur, S. M. R. Lopes, J. Harrop, and A. E. Gamble, "Study of moment redistribution in prestressed concrete beams," J. Struct. Eng., vol. 125, no. 3, pp. 351-352, Mar 1999, http://dx.doi.org/10.1061/(ASCE)07339445(1999)125:3(351).

[4] A. A. Yee and D. Hon, "Structural and economic benefits of precast/prestressed concrete construction," PCI J., vol. 46, no. 4, pp. 3442, 2001.

[5] J. C. Saemann and G. W. Washa, "Horizontal shear connections between precast beams and cast-in-place slabs," ACI J. Proc., vol. 17, no. 3, 1964, http://dx.doi.org/10.14359/7832.

[6] A. H. Mattock, Shear Transfer Under Monotonic Loading, Across an Interface Between Concretes Cast at Different Times. Seattle: Washington Univ., 1976. [Online]. Available: https://ntrl.ntis.gov/NTRL/dashboard/searchResults/titleDetail/PB275257.xhtml 
[7] J. Wairaven, J. Frenay, and A. Pruijssers, "Influence of concrete strength and load history on the shear friction capacity of concrete members," PCI J., vol. 32, no. 1, pp. 66-84, Jan 1987, http://dx.doi.org/10.15554/pcij.01011987.66.84.

[8] R. E. Loov and A. K. Patnaik, "Horizontal shear strength of composite concrete beams with a rough interface," PCI J., vol. 39, no. 1, pp. 48-69, 1994, http://dx.doi.org/10.15554/pcij.01011994.48.69.

[9] A. K. Patnaik, "Behavior of composite concrete beams with smooth interface," J. Struct. Eng., vol. 127, no. 4, pp. 359-366, Apr 2001, http://dx.doi.org/10.1061/(ASCE)0733-9445(2001)127:4(359).

[10] L. F. Kahn and A. Slapkus, "Interface shear in high strength composite T-beams," PCI J., vol. 49, no. 4, pp. 102-110, 2004, http://dx.doi.org/10.15554/pcij.07012004.102.110.

[11] M. A. Mansur, T. Vinayagam, and K.-H. Tan, "Shear transfer across a crack in reinforced high-strength concrete," J. Mater. Civ. Eng., vol. 20, no. 4, pp. 294-302, Apr 2008, http://dx.doi.org/10.1061/(ASCE)0899-1561(2008)20:4(294).

[12] A. A. Semendary, W. K. Hamid, E. P. Steinberg, and I. Khoury, "Shear friction performance between high strength concrete (HSC) and ultra high performance concrete (UHPC) for bridge connection applications," Eng. Struct., vol. 205, pp. 110-122, 2020, http://dx.doi.org/10.1016/j.engstruct.2019.110122.

[13] American Concrete Institute, Building Code Requirements for Structural Concrete, ACI 318-19, 2019.

[14] American Association of State Highway and Transportation Officials, AASHTO Bridge Design Specifications, 9th ed. Washington: AASHTO, 2020.

[15] J. P. R. Dantas, "Investigação experimental da fadiga em lajes de pontes armadas com barras ou telas soldadas,” M.S. thesis, Esc. Politéc., Univ. São Paulo, São Paulo, 2010.

[16] P. S. P. Cavalcanti, "Investigação experimental da fadiga ao cisalhamento em lajes de pontes com pré-lajes,” M.S. thesis, Esc. Politéc., Univ. São Paulo, São Paulo, 2011.

[17] E. C. Caixeta, "Investigação experimental da fadiga em lajes de pontes com ou sem pré-lajes,” M.S. thesis, Esc. Politéc., Univ. São Paulo, São Paulo, 2010.

[18] S. A. Kristiawan, "Evaluation of models for estimating shrinkage stress in patch repair system," Int. J. Concr. Struct. Mater., vol. 6, no. 4, pp. 221-230, 2012, http://dx.doi.org/10.1007/s40069-012-0023-y.

[19] H. W. Birkeland, "Differential shrinkage in composite beams," ACI J. Proc., vol. 56, no. 5, pp. 1123-1136, 1960, http://dx.doi.org/10.14359/8133.

[20] D. E. Branson, "Time-dependent effects in composite concrete beams," ACI J. Proc., vol. 61, no. 2, pp. 213-230, 1964, http://dx.doi.org/10.14359/7776.

[21] Y. Yuan and M. Marosszeky, "Restrained shrinkage in repaired reinforced concrete elements," Mater. Struct., vol. 27, no. 7, pp. 375382, Aug 1994, http://dx.doi.org/10.1007/BF02473440.

[22] J. Silfwerbrand, "Stresses and strains in composite concrete beams subjected to differential shrinkage," ACI Struct. J., vol. 94, no. 4, pp. 347-353, 1997, http://dx.doi.org/10.14359/485.

[23] Y. Yuan, G. Li, and Y. Cai, "Modeling for prediction of restrained shrinkage effect in concrete repair," Cement Concr. Res., vol. 33, no. 3, pp. 347-352, Mar 2003, http://dx.doi.org/10.1016/S0008-8846(02)00960-2.

[24] J. Zhou, G. Ye, E. Schlangen, and K. van Breugel, "Modelling of stresses and strains in bonded concrete overlays subjected to differential volume changes," Theor. Appl. Fract. Mech., vol. 49, no. 2, pp. 199-205, 2008, http://dx.doi.org/10.1016/j.tafmec.2007.11.006.

[25] S. Sullivan, "Construction and behavior of precast bridge deck panel systems," Ph.D. dissertation, Virginia Tech, Blacksburg, 2007.

[26] H. Beushausen and M. G. Alexander, "Localised strain and stress in bonded concrete overlays subjected to differential shrinkage," Mater. Struct., vol. 40, no. 2, pp. 189-199, Jan 2007, http://dx.doi.org/10.1617/s11527-006-9130-Z.

[27] R. H. Evans and A. S. Parker, "Behavior of prestressed concrete composite beams," ACI J. Proc., vol. 51, no. 5, pp. 861-878, 1955, http://dx.doi.org/10.14359/11721.

[28] N. M. Taha, A Microcomputer Program for the Design of Composite Beam. Cairo: Cairo Univ., 1978.

[29] S. Dritsos, K. Pilakoutas, and E. Kotsira, "Effectiveness of flexural strengthening of RC members," Constr. Build. Mater., vol. 9 , no. 3, pp. 165-171, Jun 1995, http://dx.doi.org/10.1016/0950-0618(95)00010-D.

[30] J.-W. Hwang, J.-H. Kwak, and H.-G. Kwak, "Finite-element model to evaluate nonlinear behavior of posttensioned composite beams with partial shear connection," J. Struct. Eng., vol. 141, no. 8, pp. 04014205, Aug 2015, http://dx.doi.org/10.1061/(ASCE)ST.1943541X.0001174.

[31] Associação Brasileira de Normas Técnicas, Projeto de Estruturas de Concreto - Procedimento, ABNT NBR 6118:2014, 2014.

[32] Associação Brasileira de Normas Técnicas, Cordoalhas de Aço para Estruturas de Concreto Protendido - Especificação, ABNT NBR 7483:2020, 2020.

[33] L. M. Silva and R. C. Carvalho "Análise de seções transversais de concreto armado e protendido sujeitas a flexão oblíqua composta em estados-limites último e de serviço por integração analítica,” Rev. Sul-Am. Eng. Estrut., vol. 16, no. 2, pp. 76-97, 2019, http://dx.doi.org/10.5335/rsaee.v16i2.8482. 
[34] L. M. Santos, Sub-Rotinas Básicas do Dimensionamento de Concreto Armado, 1a ed. São Paulo: Thot, 1994.

[35] C. Mazzotti and N. Buratti, "A design oriented fibre-based model for simulating the long-term behaviour of RC beams: Application to beams cast in different stages," J. Build. Eng., vol. 44, pp. 103176, Dec 2021, http://dx.doi.org/10.1016/j.jobe.2021.103176.

[36] M. Bottoni, C. Mazzotti, and M. Savoia, "Long-term experimental tests on precast beams completed with cast in situ concrete," Eur. J. Environ. Civ. Eng., vol. 13, no. 6, pp. 727-744, 2009, http://dx.doi.org/10.1080/19648189.2009.9693148.

Author contributions: EVWT: conceptualization, development of the computational algorithm, data analysis, writing and translation; GAP and TNB: supervision, revision, translation.

Editors: Leandro Trautwein, Antônio Carlos dos Santos 